\title{
Experiences of establishing and maintaining a community pharmacy research network
}

Elizabeth Seston, Karen Hassell, Judith Cantrill, Margaret Nicolson, Peter Noyce and Ellen Schafheutle School of Pharmacy and Pharmaceutical Sciences, University of Manchester, Manchester, UK

\begin{abstract}
The objectives are to describe the establishment of a community pharmacy research network, to give an overview of projects undertaken, to address issues around recruitment, maintenance and support, to report the findings of three postal surveys of pharmacy staff who participated in the network, and to explore views and attitudes towards research. Three self-completion questionnaires were distributed to staff in network community pharmacies over a three-year period. The questionnaires consisted of statements on attitudes to research and experiences of participating in research projects. Demographic information (employment status, gender, etc) were also collected. Network community pharmacies in the north of England participated in five research projects. The response rates to the staff surveys ranged from $100 \%$ to $53 \%$. Staff showed high levels of interest in research and enjoyed the variety of participating in projects with different data collection techniques. More than half of the sample felt that participating in research had improved relationships between staff and customers in their pharmacy. A similar percentage also felt that the quality of the advice they gave to customers improved as a result of involvement in specific projects. Data from both the projects and the questionnaires suggest that the network has achieved its aim of involving more community pharmacists in research. Further, despite changes in personnel in some of the pharmacies, attrition was low and pharmacists and their staff appeared motivated to continue their involvement in research.
\end{abstract}

Key words: community; experience; networks; pharmacy; research

\section{Introduction}

\section{Primary care research networks}

Primary care research networks are considered a useful method of engaging and training practitioners in research methodologies (Thomas et al., 2001). Although networks have been in existence for over 30 years, political acknowledgement of their significance is a more recent phenomenon. In 1997, the National Primary Care Working Group published its review, which addressed issues of low research capacity in primary care in England (Mant, 1997). The working group recommended investment in primary care research networks to 'achieve an evidence-based culture in primary

Address for correspondence: Elizabeth Seston, School of Pharmacy and Pharmaceutical Sciences, University of Manchester, Oxford Road, Manchester M13 9PL, UK.

Email: liz.seston@man.ac.uk care'. There are currently more than 30 research networks affiliated to the UK federation of primary care networks (Thomas et al., 2000).

Clement et al. define a research network as 'an organisation that aims to increase the involvement of primary care professionals in research' (Clement et al., 2000). Research networks vary considerably according to their aims, size and organizational structure. However, Clements et al. argue that most networks have 1) formal membership for either individuals or practices, 2) a co-ordinator or coordinating team and 3) a newsletter for members. Many networks also provide support and individual training in research methodologies for individual members.

Different 'models' or 'typologies' of research networks have been posited; these include 'topdown' models which are typified by strong institutional links, often to an academic department, with research projects generally led by experts and 
'bottom-up' models which are characterized by practitioners developing their own ideas, with the network often led by a peer group (Thomas et al., 2001). Although these are presented as distinct categories, in practice, many networks incorporate elements of both models.

Primary care networks have undertaken a broad range of research including collection of morbidity data, clinical research, practice-based research and large multicentre trials. Despite the breadth of the research activities of such networks, Carter et al. argued that there has been little research to determine whether primary care networks are an effective tool for promoting a research culture in primary care and called for more formal evaluation of such networks (Carter et al., 2000). It should also be noted that the term primary care network is usually assumed to refer to a network containing general practices, although networks outside this sphere are starting to develop. Community pharmacy is just one area where nascent research networks are starting to emerge.

\section{Research networks in pharmacy}

In 1997, the Pharmacy Practice Research and Development Task Force considered the current state of research and pharmacy practice (Pharmacy Practice Research and Development Task Force, 1997). In the subsequent report, they recommended that all pharmacists should be 'research users', using evidence to inform practice and improve healthcare and that $10 \%$ of practitioners should be 'research doers', actively involved as data collectors, independent researchers or participating in evaluations of new services or models of delivery.

The report of the Pharmacy subgroup to the National Health Service Research \& Development (NHS R \& D) Strategic Review Primary Care Working Group identified particular problems relating to primary care pharmacy research (Department of Health, 1999). One of the main issues to be resolved was the availability of a trained R\&D workforce and the subgroup argued that 'appropriate and sustainable involvement of practitioners in the research process probably presents ... the most urgent challenge'. According to the subgroup, problems arose in the way in which research sites and data collectors were recruited for research. Practitioners and sites are generally recruited on a project by project basis which is time consuming and can add up to a six-month timelag in some projects. The authors concluded that 'research investment in a national practitioner research framework will be crucial to developing a rigorous research base in community pharmacy'.

Such research networks have been proposed as a means of enabling robust, nationally generalizeable research to be conducted within community pharmacy (Pharmacy Practice Research and Development Task Force, 1997). The ideal model would include representatives of independent pharmacies, national multiples and smaller chains. To enable practitioners to make informed decisions about participation in research networks, such initiatives have to be evaluated.

\section{The community pharmacy research network (CPRP)}

In 1997, researchers from the School of Pharmacy, University of Manchester decided to establish a community pharmacy research network. The motivation behind this decision was twofold: first, to recruit pharmacies to collect data for shortterm projects and secondly, to test the feasibility of establishing and maintaining such a network.

Between October 1997 and April 1998, pharmacists were recruited to a research network by means of a news item in Pharmaceutical Journal (Anon, 1997), by contacting national pharmacy chains and Centre for Postgraduate Pharmacy Education (CPPE) tutors and by 'snowballing'. For logistical reasons, recruitment was confined to areas within easy access of the M62 motorway. Network members signed a formal letter of agreement with the university and agreed to participate in two research projects over a one-year period. A designated 'network' pharmacist was identified in each pharmacy. In return for agreeing to participate, they received an annual retention fee and a further 'incentive' payment related to data collection for each project. This contract was 'renewed' after the initial one-year period.

\section{Aims and objectives}

The objectives of this paper are threefold: first, to describe the establishment of a community pharmacy research network and address issues around recruitment, maintenance and support of such a network. Secondly, to provide an overview of research projects undertaken and, finally, to report the findings of three questionnaire-based surveys 
of the pharmacy staff who participated in the network to explore their attitudes to participating in research. Conclusions about the types of projects that are successful are drawn and the benefits of participation and key problems associated with being involved are identified. In doing this, it is hoped to provide relevant information for researchers and practitioners considering establishing a similar network in community pharmacy.

\section{Methods}

Prior to the start of the first study, all staff in the participating network pharmacies $(n=137)$ were asked to complete a brief questionnaire exploring attitudes to participating in research. A second questionnaire was mailed to the original sample three months after completion of projects one and two (which ran concurrently) and explored the experience of participating in these projects. Participants were asked to consider any perceived benefits to participating in the study and problems encountered. A third questionnaire was distributed to pharmacy staff after the completion of the fourth and fifth projects, which ran in parallel. This questionnaire followed broadly the same format, although more detailed questions were included about reasons for participation, preference for project types and the impact of participation. It also included open questions that allowed staff to detail the benefits and problems encountered as network members. The same demographic data were collected at all three stages.

The first and second surveys were sent to 137 staff identified by the network co-ordinator. Updates to the staff list resulted in 138 questionnaires distributed to named staff in the third survey.

\section{Results}

\section{Part I: Establishing and maintaining the community pharmacy research network}

\section{Composition}

Initially, 22 community pharmacies were recruited to the community pharmacy research network. Three of these dropped out prior to the commencement of the first study and a fourth dropped out of the study due to pressure of work, without having recruited any customers.

The network consisted of representatives from large multiples, small chain and independent pharmacies and were situated in a variety of locations, including innercity, urban, rural and suburban. The mean dispensing load was 4864 items (range: 2000-10000) and the mean NHS turnover (percentage of turnover which is NHS prescriptions) was $76 \%$ (range: $40-90 \%$ ) (see Table 1 for further details of the composition of the network).

The composition of the network altered slightly during its existence, due to two designated pharmacists taking up positions elsewhere and two new pharmacies joining.

\section{Supporting the network}

Before each project commenced, network members (usually the designated pharmacist) were invited to attend an evening meeting and were visited in person by the co-ordinator appointed to support the network (MN). The project co-ordinator played a pivotal role in the establishment and maintenance of the research network. This was a time-consuming role, which involved personal visits to each pharmacy at the beginning of each project to explain the project details. At these meetings, pharmacists and pharmacy staff would be trained in completion of data collection forms. Contact with the network members was also maintained through regular telephone calls, mailings and emails.

\section{Feedback}

Feedback to the network was initially given in the form of a lengthy written report on the first two projects and an oral presentation at the evening meetings described above. However, as the meetings were designed for pharmacists only, pharmacy staff did not always receive feedback on the projects and anecdotal evidence suggests that few nonpharmacist staff saw copies of the first written report. Therefore, for the final three projects, feedback was given in the form of a short newsletter, which was sent to all pharmacy staff. The newsletter provided overall findings from the network projects, individual data collection per pharmacy and the outcomes of the research in terms of research publications. 
Table 1 Characteristics of network pharmacies

\begin{tabular}{|c|c|c|c|c|c|c|}
\hline $\begin{array}{l}\text { Pharmacy } \\
\text { ID }\end{array}$ & Type & Location & $\begin{array}{l}\text { Monthly } \\
\text { dispensing } \\
\text { load (items) }\end{array}$ & $\begin{array}{l}\% \text { NHS } \\
\text { turnover }\end{array}$ & $\begin{array}{l}\text { Services } \\
\text { provided }^{a}\end{array}$ & $\begin{array}{l}\text { Projects } \\
\text { participated } \\
\text { in }\end{array}$ \\
\hline 01 & Large chain & Suburb & 2000 & 80 & 1 & $1,2,3$ \\
\hline 03 & Small group $(<5)$ & Town & 4000 & 90 & 1,4 & $1,2,3,4,5$ \\
\hline 04 & Independent & Suburb & 3500 & 80 & 1,2 & $1,2,3,4,5$ \\
\hline 05 & Small group $(<5)$ & Inner city & 3500 & 80 & $1,2,3$ & $1,2,3,4,5$ \\
\hline 06 & Independent & Inner city & 3500 & 75 & 1,3 & $1,2,3,4,5$ \\
\hline 07 & Independent & Suburb & 5000 & 80 & $1,2,3$ & $1,2,3,4,5$ \\
\hline 08 & Small group $(<5)$ & Suburb & 3800 & 80 & 1,2 & $1,2,3,4,5$ \\
\hline 09 & Large chain & Rural & 5000 & 85 & 1 & $1,2,3,4,5$ \\
\hline 11 & Large chain & Inner city & 5500 & 80 & 1,2 & $1,2,3,4,5$ \\
\hline 12 & Independent & Suburb & 9000 & 90 & 1,3 & $1,2,3,4,5$ \\
\hline 13 & Large chain & Town & 7200 & 87 & 1,3 & $1,2,3,4,5$ \\
\hline 14 & Large chain & Town & 3500 & 75 & 1,3 & $1,2,3,4,5$ \\
\hline 15 & Large chain & Suburb & 8500 & 80 & 3 & $1,2,3,4,5$ \\
\hline 16 & Independent & Inner city & 10000 & 41 & $1,2,3,4$ & $1,2,3,4,5$ \\
\hline 17 & Large chain & Inner city & 6000 & 40 & 1,2 & $1,2,3,4,5$ \\
\hline 18 & Large chain & Rural & 2800 & 80 & $1,3,4$ & $1,2,3,4,5$ \\
\hline 19 & Large chain & Rural & 2000 & 70 & 1,3 & $1,2,3,4,5$ \\
\hline 20 & Independent & Suburb & 2750 & 75 & $1,2,3$ & $1,2,3,4,5$ \\
\hline 21 & Large chain & Suburb & Not available & Not available & Not available & $1,2,3$ \\
\hline 22 & Small chain & Suburb & Not available & Not available & Not available & $3,4,5$ \\
\hline 23 & Independent & Suburb & Not available & Not available & Not available & 4,5 \\
\hline
\end{tabular}

aServices: 1, patient medication records; 2 , diagnostic testing; 3, services to residential and nursing homes; 4 , needle exchange services.

\section{Network projects}

Pharmacy staff at network pharmacies took part in five projects between 1998 and 2001, which varied according to data collection methods and level of involvement with customers (see Table 2 for further details):

1) Management of 'red eye' (bacterial conjunctivitis) in community pharmacies.

2) Management of thrush (vaginal candidiasis) in community pharmacies.

3) Management of diarrhoea in community pharmacies.

4) Nondispensing of prescription items in community pharmacies.

5) European network for Drug European Policies (ENDEP) - questionnaire to explore decisionmaking in relation to medication costs.

Members of pharmacy staff (usually the pharmacist) were involved in the design and piloting of data collection instruments. Medicines counter assistants from several of the network pharmacies were also involved in focus group discussions in project three. Network pharmacists also piloted a question- naire, which was subsequently sent to a national sample of community pharmacists on the management of diarrhoea.

The pressures of daily practice meant that all cases meeting the inclusion criteria were not always recruited into the studies in each pharmacy. In order to assess the completeness of data collection or patient recruitment, staff were asked to record every 'missed' customer, where a customer presented with symptoms of one of the chosen conditions but for some reason, a record form was not completed.

\section{Part II: Results of network evaluation surveys}

The response rate for survey one was $100 \%$, $56 \%$ for survey two and $53 \%$ for survey three (Table 3). Individual response rates per pharmacy varied from $0 \%$ to $100 \%$. Low response rates could be attributed to a number of factors, including designated pharmacists having left their post, large numbers of casual staff employed in larger pharmacies and high turnover of staff. 
Table 2 Project details

\begin{tabular}{l}
$\begin{array}{l}\text { Project title and Aim of project } \\
\text { No. }\end{array}$ \\
\hline
\end{tabular}

1. Management of I. To determine 'red eye' (bacterial incidence of the conjunctivitis) in community pharmacies (Parts I and II)
2. Management of thrush (vaginal candidiasis) in community pharmacies
3. Management of diarrhoea in community pharmacies (Parts I and II) in comparison to four other minor ailments (hay fever, vaginal thrush, cystitis and acne)

II. To measure the incidence of red eye cases in community pharmacy; to determine history and clinical features; pharmacy management of case and the outcome of the presentation of red eye consultation
I. As 1 (I) above II. To measure the incidence of thrush cases in community pharmacy; to determine history and clinical features; pharmacy management of case and the outcome of the consultation
1 week

Any customer who:

- Presented with symptoms of one of five conditions, or

- Requested named product used for treatment of one of five conditions, or

- Presented with self-diagnosis of one of five conditions, or

- Presented on behalf of third party with one of five conditions

8 weeks Any customer who:

- Presented with symptoms of red eye, or

- Requested named product used for treatment of red eye, or

- Presented with selfdiagnosis of red eye, or

- Presented on behalf of third party with red eye

As above As above

8 weeks Any customer who:

- Requested named

I. To determine

1 week incidence of diarrhoea in comparison with four other minor ailments (indigestion, red eye, head lice and cold sore)
Data collection
form only

$n=607$

Hay fever $=459$

Thrush $=62$

Red eye $=43$

Cystitis $=33$

Acne $=10$

Data collection form ${ }^{\text {a }}$

$n=125$

Missed cases $=59$

Contact details

obtained $=75$

Customers

interviewed $=46$
- Presented with symptoms of thrush, or product used for treatment of thrush or

- Presented with selfdiagnosis of thrush or

- Presented on behalf of third party with thrush

As above

Data collection form $^{\text {a }}$

Telephone

interviews

Any customer who:

- Presented with symptoms of one of five conditions, or

- Requested named product used for treatment of one of five conditions, or

- Presented with selfdiagnosis of one of five conditions, or

- Presented on behalf of third party with one of five conditions
Data collection form only ${ }^{a}$
As above $n=209$

Missed cases $=67$

Contact details

obtained $=100$

Customers

interviewed $=31$ $n=288$

Diarrhoea $=80$ Indigestion $=71$

Red eye $=49$

Head lice $=48$

Cold sore $=40$ 
Table 2 Continued

\begin{tabular}{llll}
\hline $\begin{array}{l}\text { Project title } \\
\text { and No. }\end{array}$ & Aim of project & Duration Inclusion criteria & $\begin{array}{l}\text { Method of data Results } \\
\text { collection }\end{array}$
\end{tabular}

II. To determine the
incidence, presenting
characteristics,
management and
outcome of diarrhoea
in community
pharmacies; to explore
the beliefs of counter
assistants and
pharmacists regarding
management of this
condition

\begin{abstract}
4. Nondispensing of prescription

To establish the extent of items in community nondispensing of pharmacies

prescription items in community pharmacies; to explore the nature of this process
\end{abstract}

5. European Survey of Health and Health Care Costs

To explore how and to what extent charges incurred by

4 weeks

Any customer who:

- Presented with symptoms of diarrhoea, or

- Requested named product used for treatment of diarrhoea, or

- Presented with self-diagnosis of diarrhoea, or

- Presented on behalf of third party with diarrhoea

6 weeks

Any customer who:

- Presented a prescription and asked for one or more items not to be dispensed, or

- Presented a prescription and a member of pharmacy staff suggested nondispensing of the item patients influence the decision making of consumers to utilize primary care services (Carried out as the UK part of a study by the Evaluation Network for Drug European Policy (ENDEP))

- Received
Any customer who:

\section{6-12}

weeks prescription medicines for hypertension and who was not exempt from prescription charges, or

- Received prescription medicines for dyspepsia and who was not exempt from prescription charges or

- Purchased an over the counter product for dyspepsia
Data collection $\quad n=122$

form ${ }^{\text {a }}$

Telephone

interviews

Counter

assistant focus

groups ( $n=12$ )

National survey of pharmacists

( $n=1401)$

Data collection

form only
Missed cases $=87$

Contact details obtained $=32$ Customers interviewed $=22$ Survey response rate $=59$ per cent

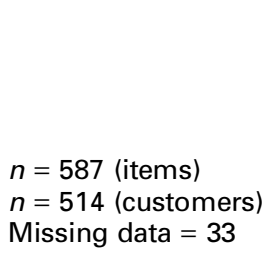

Questionnaires distributed to customers with hypertension and dyspepsia who met inclusion criteria $^{\mathrm{a}}$

Hypertension: questionnaires distributed $=277$, returned $=134$ (response rate: 48\%) Dyspepsia: questionnaires distributed $=296$, returned $=110$ (response rate: $37 \%)$

a Undertaken by pharmacy staff. 
Table 3 Demographic details of the survey respondents

\begin{tabular}{llll}
\hline & $\begin{array}{l}\text { Survey } 1 \\
n=137 \\
(\%)\end{array}$ & $\begin{array}{l}\text { Survey } 2 \\
n=77 \\
(\%)\end{array}$ & $\begin{array}{l}\text { Survey 3 } \\
(\%)\end{array}$ \\
\hline $\begin{array}{l}\text { Pharmacist } \\
\text { Medicines counter }\end{array}$ & 29 & 35 & 29 \\
assistant & 46 & 41 & 42 \\
Dispenser & 25 & 24 & 29 \\
$\begin{array}{l}\text { Female } \\
\text { Male }\end{array}$ & 87 & 89 & 86 \\
'Interested' in research & 13 & 11 & 14 \\
\hline
\end{tabular}

Involvement in the decision to take part in the Network

In survey three, participants were asked to record whether they were involved in 1) the decision to take part in the network and 2) the arrangements for setting up the network. The findings suggested significantly different levels of involvement in the decision to participate in the network. Overall, $36 \%$ of the sample was involved in the decision to participate. Pharmacists were significantly more likely than other pharmacy staff to be involved in this decision ( $65 \%$ versus $20 \% ; \chi^{2}$ $=13.516, \mathrm{df}=1, P=0.000)$. Similar figures were found for involvement in the arrangements for setting up the network projects, with pharmacists again more likely to be involved in this than other pharmacy staff $\left(75 \%\right.$ versus $20 \% ; \chi^{2}=18.321, P$ $=0.000$ ).

\section{Attitudes to research}

Participants in all three surveys were asked to characterize their attitudes towards pharmacy practice research. Similar findings were found for this attitude statement across the three surveys, with the highest agreement figure (86\%) in the final survey (see Table 3). There were no significant differences in attitudes to research according to gender.

In the second survey, staff were asked to consider their experience of participating in the panel. The majority $(75 \%)$ agreed that they had found the first project interesting and the remainder were neutral. In terms of how much work had been involved in project one, $68 \%$ thought that it had been what they expected and more than a quarter thought that it had actually involved less work.
Only $4 \%$ felt that participating in the research had been more onerous than anticipated.

\section{Reasons for involvement in the network}

'Interest in research' was the key reason for involvement in network projects $(85 \%)$, although 'improving job satisfaction' and 'good for pharmacy image' also scored highly. Remuneration was noted as a positive factor by almost two thirds of respondents.

\section{Preferences for different project types}

Participants clearly enjoyed participating in a variety of different projects and despite anecdotal evidence that they felt uncomfortable asking for customer contact details, more than half the sample said they enjoyed projects where they were able to speak to the customer.

\section{Impact of participation in research}

Participants were asked to consider whether participation in the research network had had any impact on their daily practice. Just over half (56\%) felt that participating in the research network had improved the relationships between staff and customers and this view was supported by some of the responses to open-ended questions in the questionnaire:

Our customers know that we are taking a genuine interest in their problems

(Medicines Counter Assistant)

Each customer involved in the project had more attention, which I found gave me great satisfaction

(Medicines Counter Assistant)

A similar proportion (55\%) felt that the quality of advice they gave when making over the counter sales had also improved due to their involvement in research:

Improved awareness of treatment response to symptoms and encouraged the asking of questions by assistants, thereby benefiting service provided

(Medicines Counter Assistant)

This perceived improvement in the quality of advice giving is supported by the fact that almost half $(47 \%)$ of respondents felt that participation in research had improved their knowledge of the 
management of the specific minor ailments. Medicines counter assistants and dispensers were significantly more likely to agree that their knowledge had improved than pharmacists (54\% versus $29 \%$, $\left.P=0.05, \chi^{2}=3.840\right)$.

In earlier research on pharmacists' attitudes to participation in research, academic researchers were criticized for failing to appreciate the realities of day-to-day practice in community pharmacy when designing research studies (Rosenbloom et al., 2000). In our study, over half the sample $(57 \%)$ felt that the researchers understood the difficulties of collecting data in community pharmacy.

Additional benefits of involvement in the network, which were identified in the open comments section of the questionnaire, included: increased knowledge, increased staff awareness, improved staff motivation and satisfaction from involvement in pharmacy research. The following quotes further illustrate some of these issues:

I understand more about the product. Both from the customer point of view and also from the pharmacy point of view (Medicines Counter Assistant)

Kudos (if that's the correct word!) of being linked with a University by staff and customers. Makes you more aware of amount of queries/advice that takes place

(Pharmacist)

\section{Feedback}

The preferred method of receiving feedback on the network projects in both surveys two and three was a brief newsletter. This supports anecdotal evidence from network members, which suggested that they found the newsletters informative and interesting and liked getting feedback. Fifty-four per cent of respondents felt that receiving a newsletter about the network projects encouraged them to participate in research.

\section{Main problems}

Respondents were also asked to identify the key problems with the research projects. These included: remembering to fill in forms when busy, customer reluctance to give out personal information, targeting the right customers for distributing questionnaires, time, ensuring adequate supervision of staff and getting information from customers presenting on behalf of a third party.

Many of the staff reported feeling uncomfortable about asking for personal details, as this quote illustrates:

Uncomfortable asking for participants' telephone numbers - often forms were filled in after patient had left the pharmacy

(Medicines Counter Assistant)

For the pharmacist, the research could cause logistical or practical problems and it could be difficult to keep staff motivated to keep an accurate record of minor ailment queries:

Motivation of staff when locum/holiday cover not as good as when principals in post

(Pharmacist)

Required effort on my part to ensure that all staff are recording all enquiries during data collection period

(Pharmacist)

The anticipated realities of community pharmacy practice meant that often staff found it difficult to record data when the pharmacy was busy:

When the shop was busy we couldn't really do the questionnaire as we didn't have any time and other customers needed to be served (Medicines Counter Assistant)

\section{Incentive payments}

The incentive payments were designed to keep the pharmacy staff interested and make them feel their efforts in collecting data were appreciated. A payment of $£ 5$ was made per completed data collection form for projects one to four and $£ 3$ for each questionnaire returned for project five. The incentive payments were intended for all of the pharmacy staff collectively and were designed to be spent in such a way that everyone who participated would benefit.

In the second survey, participants were asked whether they felt the financial incentives had made any impact on patient recruitment. More than $70 \%$ felt that this had had no impact on recruitment levels. In the final survey, participants were asked to record how the money they had received had been used in their pharmacy. In the majority of the network pharmacies, the staff used the money they 
had received in a variety of innovative ways, including day trips for staff, work-related clothing and electrical items for the pharmacy. However, in a number of cases, staff reported that they had not received any benefit from the payments.

One respondent from a multiple pharmacy responded 'What money?!' when asked how the money had been spent in their pharmacy. The pharmacist at another multiple pharmacy made the following comment:

Payment no doubt sent to and swallowed by our head office - ongoing saga. No money received at branch yet, therefore not spent

(Pharmacist)

This is unfortunate as the payments were designed to act as an incentive for all the staff who were actively involved in both the collection of the data and the success of the projects.

\section{Discussion}

Over the three-year period in which the network has operated, network pharmacies have taken part in five short-term research projects, utilizing a variety of data collection methods, which resulted in five published papers in peerreviewed journals (Chapple et al., 2000; Schafheutle et al., 2002; Seston et al., 2001a; 2001b; 2001c). Data from both the projects and the questionnaires suggest that the network has achieved its aim of involving more community pharmacists in research. Further, despite changes in personnel in some of the pharmacies, attrition was low and pharmacists and their staff appeared motivated to continue their involvement in research.

Communicating regularly with the network members was a key factor in maintaining this motivation. Personal visits to network pharmacies prior to the commencement of projects and regular telephone contact enabled network members to be kept up to date with developments. Feedback on network projects was given in three forms: through a written report, at annual meetings of the network pharmacists and, after project three, via a newsletter. This latter method was felt by network members to be the most effective way of providing feedback.

With the aim of rewarding pharmacy staff for their involvement in the network, a system of fin- ancial incentives was an integral part of the agreement between the university and network members. In addition to the fixed sums received for participation, they also received a small payment depending on the levels of recruitment for each individual project in their pharmacy. It was explicitly stated in the documentation sent to the network pharmacies that this payment should be used for the benefit of the staff who were involved in the research. Although there is no evidence to suggest that the existence of these incentive payments had any impact on data collection per se, comments from the third survey indicated that these payments were regarded as a goodwill gesture, which encouraged commitment to the network.

Conversely, in the pharmacies where staff did not see the benefit of this money, there was some evidence of resentment. In particular, this may impact on the future willingness of pharmacy staff to participate in data collection.

Previous research has highlighted the key role that medicines counter assistants and dispensers play in patient management within the pharmacy (Seston et al., 2001b; Ward et al., 1998). In particular, in any research project on the management of minor ailments, medicines counter assistants are likely to be the key data collectors. It is positive therefore, that some pharmacists in the network chose to include their staff in the decision to participate in the network. While it is not possible to assess whether involvement in the decision to participate had a positive impact on data collection, anecdotal reports suggests that these staff may have felt more motivated to participate.

One of the key limitations of the community pharmacy research network has been the generalizability of findings. Although efforts were made to ensure that the network contained a mix of independent, small chain and multiple pharmacies, the network was limited by size, geographical and financial considerations. It is arguable that it would have been difficult to maintain the same levels of personal contact and communication had the network been established on a larger scale. In a recent study designed to evaluate the safety of a prescription only medicine (POM) in an over the counter environment, a sample of 45 community pharmacies were used and the authors concluded that it was possible to conduct a community-based trial of a POM product (Gibb et al., 2001). This 
suggests that it may be possible to operate similar network studies on a wider scale. However, the fact that all the pharmacies in their study belonged to the same multiple pharmacy, which facilitated communication and ensured consistency of systems, make this study very different from one involving a more diverse sample of independent, small chain and multiple pharmacies.

Another example of a pharmacy research network is the Hull and East Riding Pharmacy network (Anon, 2001). This network was established in 2001 and aims to co-ordinate and support all pharmacy practice research in the area, to establish six community pharmacy research practices, to support pharmacy practice research projects as learning vehicles for research skills, to design mechanisms for spreading evidence from research into practice and to network with other health service research groups across the region. Although this network is still in its early stages, four community pharmacy research practices have already been established. Several of the members of the Hull and East Riding network were also original members of the University of Manchester community pharmacy research network.

Only a limited number of studies have explored community pharmacist attitudes to and/or willingness to participate in research (Ellerby et al., 1993; Liddell, 1996; Rosenbloom et al., 2000) and there is no published evidence that the views of other nonpharmacist staff have ever been considered. In general, the pharmacy staff in our study showed higher levels of interest in research than in these studies. However, this result should be approached with caution, as the staff surveyed were self-selected and therefore unrepresentative, particularly the pharmacists, who had already indicated an interest in research by joining the network.

The most recently published study of community pharmacists' attitudes to research found that a common complaint was that academic researchers had a poor understanding of the reality of community pharmacy and that this could affect their likelihood of taking part in research (Rosenbloom et al., 2000). In our network study, more than half of respondents agreed that the researchers understood the difficulties of collecting data in a community pharmacy setting. Community pharmacy, with its commercial pressures, is a very different environment from a general practice. Researchers need to understand the context within which any professional group operates if research networks are to develop successfully.

On the whole, participants found the experience of participating in a research network a positive one. Qualitative comments from the staff surveys suggest that many of those who took part felt they had benefited from participation. Benefits they identified included: improved relationships with customers, better quality of advice given and a greater understanding of pharmacy practice research.

The findings of the study, to date, suggest that we have developed an effective model for managing and incentivizing a network of research pharmacists. Importantly, the network pharmacies demonstrate diverse ownership arrangements. By using a simple point of sale instrument, useful data on the incidence of minor ailments and their management within community pharmacies have been collected and customers successfully recruited for follow-up studies. No unforeseen problems were reported and participants volunteered some benefits from the study, which had not been anticipated at the outset. Contrary to expectations of pharmacists and staff, data collection was not unduly onerous or disruptive and, by acting as a focus for staff training, involvement in the study indicates benefits for the service and the professional image of pharmacies involved.

\section{References}

Anon 1997: Community pharmacy research panel. Pharmaceutical Journal 259, 592.

Anon 2001: Hull and East Riding community pharmacy network. Retrieved 12 September, 2001, from: http://www. hull.ac.uk/php/nssrac/Woren/pharmacy.html

Carter, Y.H., Shaw, S. and Sibbald, B. 2000: Primary care research networks: an evolving model meriting national evaluation. British Journal of General Practice 50, 859-60.

Chapple, A., Hassell, K., Nicolson, M. and Cantrill, J.A. 2000: 'You don't really feel you can function normally': women's perceptions and personal management of vaginal thrush. Journal of Reproductive and Infant Psychology 18, 309-19.

Clement, S., Pickering, A., Rowlands, G., Thiru, K., Candy, B. and de Lusignan, S. 2000: Towards a conceptual framework for evaluating primary care research networks. British Journal of General Practice 50, 651-52. 
Department of Health 1999: NHS R\&D strategic review primary care working group: report of the pharmacy subgroup. London: HMSO.

Ellerby, D.A., Williams, A. and Winfield, J. 1993: The level of interest in pharmacy practice research among community pharmacists. Pharmaceutical Journal 251, 321-22.

Gibb, I.A., Miller, K., Veltri, J.C., Page, B.A., Kellet, N. and Charlesworth, A. 2001: Using community pharmacies to evaluate the safety of a prescription-only medicine in an OTC environment: a unique method in Europe. International Journal of Pharmacy Practice 9 (Suppl), R10.

Liddell, H. 1996: Attitudes of community pharmacists regarding involvement in practice research. Pharmaceutical Journal 256, 905-907.

Mant, D. 1997: $R \& D$ in primary care: national working group report. London: HMSO.

Pharmacy Practice Research and Development Task Force 1997: A new age for pharmacy practice research: promoting evidence-based practice in pharmacy. London: Royal Pharmaceutical Society of Great Britain.

Rosenbloom, K., Taylor, K. and Harding, G. 2000: Community pharmacists' attitudes towards research. International Journal of Pharmacy Practice 8, 103-10.

Schafheutle, E.I., Hassell, K., Seston, E.M. and Noyce, P.R. 2002: Nondispensing of NHS prescriptions in community pharmacies. International Journal of Pharmacy Practice 3, 11-16.

Seston, E.M., Nicolson, M., Cantrill, J.A., Hassell, K. and Noyce, P.R. 2001a: Community pharmacy management of acute diarrhoea in adults. International Journal of Pharmacy Practice 9, 1-8.

Seston, E.M., Nicolson, M., Hassell, K., Cantrill, J.A. and Noyce, P.R. 2001b: 'Not just someone stood behind the counter': the views and experiences of medicines counter assistants. Journal of Social and Administrative Pharmacy 18, 122-28.

Seston, E.M., Nicolson, M., Hassell, K., Cantrill, J.A. and Noyce, P.R. 2001c: Variation in the incidence, presentation and management of nine minor ailments in community pharmacy. Pharmaceutical Journal 266, 429-32.

Thomas, P., Griffiths, F., Kai, J. and O'Dwyer, A. 2001: Networks for research in primary health care. British Journal of General Practice 322, 588-90.

Thomas, P., Kai, J., O'Dwyer, A. and Griffiths, F. 2000: Primary care groups and research networks: opportunities for R\&D in context. British Journal of General Practice 50, 91-92.

Ward, P.R., Bissell, P. and Noyce, P.R. 1998: Medicines counter assistants: roles and responsibilities in the sale of deregulated medicines. International Journal of Pharmacy Practice 6, 207-15. 